\title{
ASTROINFORMATICS
}

DOI: http://dx.doi.org/10.18524/1810-4215.2018.31.144734

\section{THE CATALOGUES ANALYSIS OF STARS EQUATORIAL COORDINATES AND B-MAGNITUDE OF THE FON PROJECT}

\author{
V. S. Akhmetov ${ }^{1}$, S. V. Khlamov ${ }^{1}$, V. M. Andruk ${ }^{2}$, Yu. I. Protsyuk ${ }^{3}$ \\ ${ }^{1}$ Institute of Astronomy, V. N. Karazin Kharkiv National University, \\ Kharkiv, Ukraine,akhmetovvs@gmail.com,sergii.khlamov@gmail.com \\ 2 Main Astronomical Observatory, National Academy of Sciences of Ukraine, \\ Kiev, Ukraine,andruk@mao.kiev.ua \\ ${ }^{3}$ Research Institute: Mykolaiv Astronomical Observatory, \\ Mykolaiv, Ukraine,yuri@nao.nikolaev.ua
}

ABSTRACT. FON project was expected a catalogue of stellar positions and B magnitude of Northern sky from combination six astronomical observatories of the former USSR were equipped with the same wide-angle astrographs: Goloseevo (Ukraine), Zvenigorod, Zelenchuk (Russia), Abastumani (Georgia), Kitab (Uzbekistan) and HisorAO (Tajikistan). This paper has been presented the comparison results of three catalogues (FON-KIEV, FONKITAB and FON-DUSHANBE) were received as result of scanning and astrometric reduction of photographic plates in the coordinate system of Tycho-2 catalogue. The data of zero zone (from -2 to 2 degrees of declination) from the mentioned catalogues was used during the research.

The number of common objects after cross-match of catalogues with a circular search window equals to 1.5 arc seconds was more than 500 thousands. The estimation of random accuracy of stars positions from the mentioned catalogues was performed by the Wielen method. Final dispersions were calculated for every sub-range of magnitudes. The stars with individual differences of position and magnitude that exceed three standard deviations were rejected.

The data from catalogues PMA was used for estimation of the systematic errors. It is obvious that the internal estimates of position accuracy of stars in the compared catalogues are low in one or all catalogues, and additional research is required. Analysis of the behavior of the systematic differences and standard deviations of the stellar positions of these catalogues have shown that there are a big values reaching 1 arcsec only in small sky regions. However, the internal estimation of accuracy that presented in catalogues is well matched with the systematic differences and standard deviations in the other sky regions.

Keywords: Astrometry, astrometry-catalogue, photographic plates, data analysis.

АБСТРАКТ. Проект FON передбачав створення каталогу положень та В зоряних величин північного неба шляхом об'єднання фотографічних спостережень отриманих на ширококутних астрографах 6 різних обсерваторій СРСР: Київ (Україна), Звенигород, Зеленчеук (Росія), Абастумані (Грузія), Кітаб (Узбекестан) та Гіссар АО (Таджикістан). В роботі представлені основні результати порівняння трьох фотографічних каталогів (FON-KIEV, FON-KITAB та FONDUSHANBE), що отримані в результаті сканування та астрометричної редукції фотографічних пластинок в систему положень каталогу Тусho2. Для дослідження вище наведених каталогів були використані дані нульової зони (від -2 до 2 градусів схилення).

Кількість спільних об'єктів після проведення координатного ототожнення даних каталогів, 3 круговим вікном пошуку рівним 1,5 секунд дуги, становить більше ніж 500 тисяч. Оцінка випадкової точності позицій зірок згаданих каталогів була виконана методом Вільєна. Остаточні оцінки випадкових похибок положень зірок були розраховані для кожного діапазону зоряних величин. Об'єкти з індивідуальними різницями положень, які перевищують три стандартні відхилення, не використовувались в обчисленні.

Дані $з$ каталогів РМА були використані для оцінки системних помилок. Очевидно, що внутрішні оцінки точності позицій зірок у порівнюваних каталогах $є$ заниженими в одному або всіх каталогах, і необхідні додаткові дослідження. Аналіз поведінки систематичних відмінностей та стандартних відхилень положень зірок цих каталогів показав, що є великі значення, що досягають 1 секунди дуги, тільки в малих ділянках небесної сфери. Проте внутрішня оцінка точності, представлена в каталогах, добре узгоджується з систематичними відмінностями та стандартними відхиленнями для більшої частини досліджуваної небесної сфери.

Ключові слова: астрометрія, астрометричні каталоги, фотопластинки, аналіз даних.

\section{Introduction}

In 1976, the researchers of MAO AS USSR have proposed a FON project of photographic survey of the Northern sky. This project was aimed at clarifying and extending of the existing system of proper motions of stars to the region of weak stellar magnitudes. As a result, it was ex- 
pected to obtain a highly accurate uniform coordinate system, which will be used for solving the modern problems of astrometry, celestial mechanics, astrophysics and other directions in the astronomy.

One of the favorable factors in the development of the project was a fact that in the 70s of the last century many astronomical observatories of the former USSR were equipped with the same wide-angle astrographs of the Karl Zeiss (Jena) company with an aperture of $40 \mathrm{~cm}$ and a focal length of 2 or 3 meters. The following observatories took a place in the FON project: Goloseevo (Ukraine), Zvenigorod, Zelenchuk (Russia), Abastumani (Georgia), Kitab (Uzbekistan) and GisAO (Tajikistan). All of them were divided into four groups. The Northern sky was supposed to be photographed four times with overlapping. The observations were carried out with an exposure whose duration ensured usable for measuring images of stars up to 16-17 magnitude. This work distribution among observatories gave an advantage to the FON project compared to the zone observations such as NPM and SPM. Namely, each star will be photographed at least four times by different telescopes from different places, which is very important for eliminating systematic errors in the future catalogue.

Unfortunately, due to the well-known situation of the 90s of the last century, the observations and work on the FON project were terminated. However, with help of the efforts of institutes' staff the photographic plates, records and files of the FON project have been kept in a good condition. A few years ago, in MAO NASU, the work on the FON project was restored by supporting of the Ukraine Virtual Observatory (Vavilova et al., 2012). The first catalogue, which was digitized and processed is the FON-KIEV catalogue. The approbation of technique for scanning and processing of the photographic plates was performed with this catalogue. Professional scanners and original scanning methods were used for scanning (Andruk et al., 2015). Processing of the received images was carried out by a unique algorithm developed by the MAO NASU researcher V. M. Andruk using the MIDAS/ROMAFOT environment (Andruk, 2016a; Andruk, 2016b; Andruk, 2017). Astrometric reduction of all objects in the equatorial coordinate system $(\alpha, \delta)$ of the Tycho- 2 catalogue at the epoch of observation was done. Photometric reduction of instrumental values magnitude into the system of photoelectric B-magnitudes was done (Andruk et al., 2015). The data of zero zone (from -2 to 2 degrees of declination) from the FON-KIEV, FON-KITAB and FONDUSHANBE catalogues was used in this research.

\section{Estimation of external accuracy of the star posi-} tions

The method used for estimation of external accuracy of the star positions was described by Wielen in 1995 (Wielen, 1995). It is very robust under condition of independence of the compared data. In such case the dispersion of the differences of positions or photometry is equal to the sum of their dispersions because their correlation coefficient is zero. With three or more independent catalogues it is easy to estimate the external accuracy of each of them:

$$
\begin{aligned}
& \sigma_{1}=\sqrt{\frac{D_{12}+D_{13}-D_{23}}{2}} \\
& \sigma_{2}=\sqrt{\frac{D_{12}+D_{23}-D_{13}}{2}} \\
& \sigma_{3}=\sqrt{\frac{D_{13}+D_{23}-D_{12}}{2}}
\end{aligned}
$$

where $D_{12}, D_{13}$ and $D_{23}$ are the dispersions of differences of positions or magnitudes for three compared catalogues.

Before the calculation of dispersions one should test that the correct values are obtained. The possible source of the incorrectness is an assumption that the means of initial values are zero in the case when catalogues with systematic errors have some non-zero means. Therefore it is important to determine the behavior of the systematic differences. Fortunately, in most cases the systematic differences of researched values are some smooth functions that can be calculated and excluded. Finally, in our case the dispersions are calculated by iteration method for every small range of magnitude with rejection of the stars with individual difference less than 3 standard deviations.

For analysis by mean of Wielen method the FONKIEV, FON-KITAB, FON-DUSHANBE catalogues have been used. We also used data from PMA and GaiaDR2 (Gaia collaboration, 2018) catalogues for the comparison and cross-identification of objects.

\section{Catalogues}

\subsection{FON-KIEV catalogue}

The FON-KIEV is a catalogue of star positions and Bmagnitudes of stars from the Northern Sky Survey project (from $-4^{\circ}$ to $+90^{\circ}$ ), which was created by V. Andruk, L. Pakuliak, V. Golovnia, G. Ivanov, A. Yatsenko, S. Shatokhina, O. Yizhakevych (Andruk et al., 2015; 2016a; $2016 \mathrm{~b})$. It has been created under the motto of rational use of the resources accumulated in UkrVO JDA (Joint Digital Archive) in MAO NASU. The catalogue contains 19 451751 stars and galaxies with $B=16.5^{\mathrm{m}}$ for the epoch of 1988.1 year. The coordinates of stars and galaxies were obtained in the Tycho-2 reference system, and B-value in the system of photoelectric standards. The internal accuracy of the catalogue for all objects is $\sigma_{\alpha \delta}=0.23$ " and $\sigma_{\mathrm{B}}=$ $0.14^{\mathrm{m}}$ (for stars in the range of $\mathrm{B}=7^{\mathrm{m}}-14^{\mathrm{m}}$ errors are $\sigma_{\alpha \delta}$ $=0.10^{\prime \prime}$ and $\sigma_{\mathrm{B}}=0.07^{\mathrm{m}}$ ).

\subsection{FON-KITAB catalogue}

The FON-KITAB is a catalogue of equatorial coordinates and B-magnitudes of the Kitab's part of the FON project, which was created by Q. Yuldoshev, Yu. Protsyuk, H. Relke, Sh. Ehgamberdiev, M. Muminov, V. Andruk (Yuldoshev et al., 2018).

The photographic plates of the FON project were exposed on the double telescope DAZ (Double Zeiss Astrograph, $\mathrm{D} / \mathrm{F}=40 / 300,69^{\prime \prime} / \mathrm{mm}$ ) at the Kitab observatory of the Republic of Uzbekistan. The number of the photographic plates used for the catalogue is 1963. The catalogue contains near 13.4 million stars and galaxies in the 
sky from $0 \circ$ to $-20^{\circ}$ according to declination down to $\mathrm{B}=$ $17.5^{\mathrm{m}}$ at the middle epoch of observation as 1985.0 year. The mean internal errors of the new catalogue for all objects are $\sigma_{\alpha \delta}=0.23^{\prime \prime}$ and $\sigma_{\mathrm{B}}=0.15^{\mathrm{m}}$ (for the stars in the range of $\mathrm{B}=5^{\mathrm{m}}-14^{\mathrm{m}}$ the errors are $\sigma_{\alpha \delta}=0.085^{\prime \prime}$ and $\sigma_{\mathrm{B}}=0.054^{\mathrm{m}}$ ) (Yuldoshev et al., 2017a; 2017b).

\subsection{FON-DUSHANBE catalogue}

The FON-DUSHANBE is a small equatorial realization of the project "FON-DUSHANBE catalogue" created by A. Mullo-Abdolov, H. Relke, G. Kokhirova, Q. Yuldoshev, Yu.Protsyuk, V. Andruk (Mullo-Abdolov et al., 2017).

Since May 2018 the process of the scanning and processing of photographic plates from the archive of Institute of Astrophysics Academy of Sciences of Tajikistan has begun. It is a matter of approximately 1560 photographic plates in the sky regions from $-8^{\circ}$ to $+90^{\circ}$ that were exposed for the FON project in the Hissar observatory (HisAO) during 1985-1992 years. The size of the photographic plates is $8^{\circ} \times 8^{\circ}$ or $30 \times 30 \mathrm{~cm}$, the size of the digitized images is $13000 \times 13000 \mathrm{px}$. So far the first results of the processing of the 71 plates of zero zone and the 58 plates of 64,68 and 72 zones were obtained. The errors in the definition of 29 equatorial coordinates and Bmagnitudes for the stars in the range of $5^{\mathrm{m}}-17^{\mathrm{m}}$ are the following: $\sigma_{\alpha \delta}= \pm 0.33$ " and $\sigma_{\mathrm{B}}= \pm 0.12^{\mathrm{m}}$. The differences between the calculated positions and B-magnitudes and the reference one from the Tycho- 2 catalogue are $\sigma_{\alpha \delta}=$ \pm 0.12 " and $\sigma_{\mathrm{BT}}= \pm 0.19^{\mathrm{m}}$ respectively. The difference between the calculated and the photoelectric B-magnitudes equals to $\sigma_{\mathrm{B}}= \pm 0.15^{\mathrm{m}}$.

\subsection{PMA catalogue}

The PMA catalogue (Akhmetov et al., 2017) contains about 421 million absolute proper motions of stars. It was derived from the combination of positions from Gaia DR1 and 2MASS, with a mean difference of epochs of about 15 years. Most of the systematic zonal errors inherent in the 2MASS catalogue were eliminated before deriving the absolute proper motions. The absolute calibration procedure was carried out using about 1.6 million positions of extragalactic sources. The mean formal error of the absolute calibration is less than 0.35 mas/yr. The RMS error of proper motions depends on the stellar magnitude and ranges from 2-5 mas/yr for stars with $10 \mathrm{mag}<\mathrm{G}<17$ mag to 5-10 mas/yr for faint ones.

\section{Cross-identification of objects}

In this paper the star magnitudes of all described catalogues were not used for cross-identification because of a significant difference in their band-pass, significant random and systematic errors of photometry. The crossidentification was carried out using only coordinates of objects. It should be noted that such cross-identification is usually named positional association and is not necessarily an exact identification.
At the first step all positions of each object in PMA catalogue was calculated to the means epoch of FON-KIEV, FON-KITAB, FON-DUSHANBE catalogues respectively.

The second step of cross-identification was a simple cross-match: each object of the PMA catalogue was compared with the object of the FON-KIEV, FON-KITAB, FON-DUSHANBE catalogues with circular window size of 1.5 arcsec by means of special software (Akhmetov et al., 2018). Then corresponded proper motion of PMA objects was compared with the objects from FON catalogues. This procedure was needed because of existing of large difference between the mean epoch of FON-KITAB (about 1983.7 year) and FON-KIEV or FONDUSHANBE (about 1990.4 year) and also the significant scatter of epochs in each catalogues in range 4-12 years. The base epoch we used is equal to 1990.37 year as a mean epoch of FON-KIEV. All data from FON-KITAB and FON-DUSHANBE were reduced to this epoch by means of proper motion of PMA catalogue. The next step of cross-identification was a search of the common objects for pairs FON-KIEV and FON-DUSHANBE. We used the following rule: if an angular distance is less than 1.0 arcsec it is a common object. The results of this crossidentification procedure of FON-KIEV and FONDUSHANBE catalogues we compared with stellar position of FON-KITAB catalogue with circular window size of 1.0 arcsec. This cross-identification procedure made it possible to obtain lists of pairs of stars from all three catalogues. As a result of the FON-KIEV-DUSHANBEKITAB data more than 500 thousands common stars have been obtained in declination zone $-2^{\circ}$ to $2^{\circ}$ and then inserted to database for analysis. The position difference between FONs catalogues produced mainly only by the difference between random and systematic errors of objects in catalogues.

\section{The estimation results of external accuracy and} systematic errors data of catalogues

For the quality analysis of stellar equatorial coordinates of FON project catalogues the different tests have been made. Some results of this investigation of the FONKIEV, FON-KITAB and FON-DUSHANBE catalogues are presented below. The comparison of the stellar positions of FON project catalogues is shown in figure 1. It represents the systematic differences of positions in the sense of FON-KIEV minus FON-DUSHANBE, FONKIEV minus FON-KITAB and FON-DUSHANBE minus FON-KITAB catalogues.

The mean values of systematic differences of positions in right ascension are less than 15 mas in the both coordinates and are increasing for faintest stars up to 50-75 mas for right ascension and up to 25-40 mas for declination. As showed in figure 1, the stars position of all FON project catalogues are good agreement in magnitude range of Tycho-2 stars that were used for astrometric reduction. This behavior of differences in the stars positions is associated with a significant brightness equation on photographic plates. Therefore, to eliminate the brightness equation, it is necessary to use during the reduction a reference catalogue, which covers the entire range of magnitudes. 

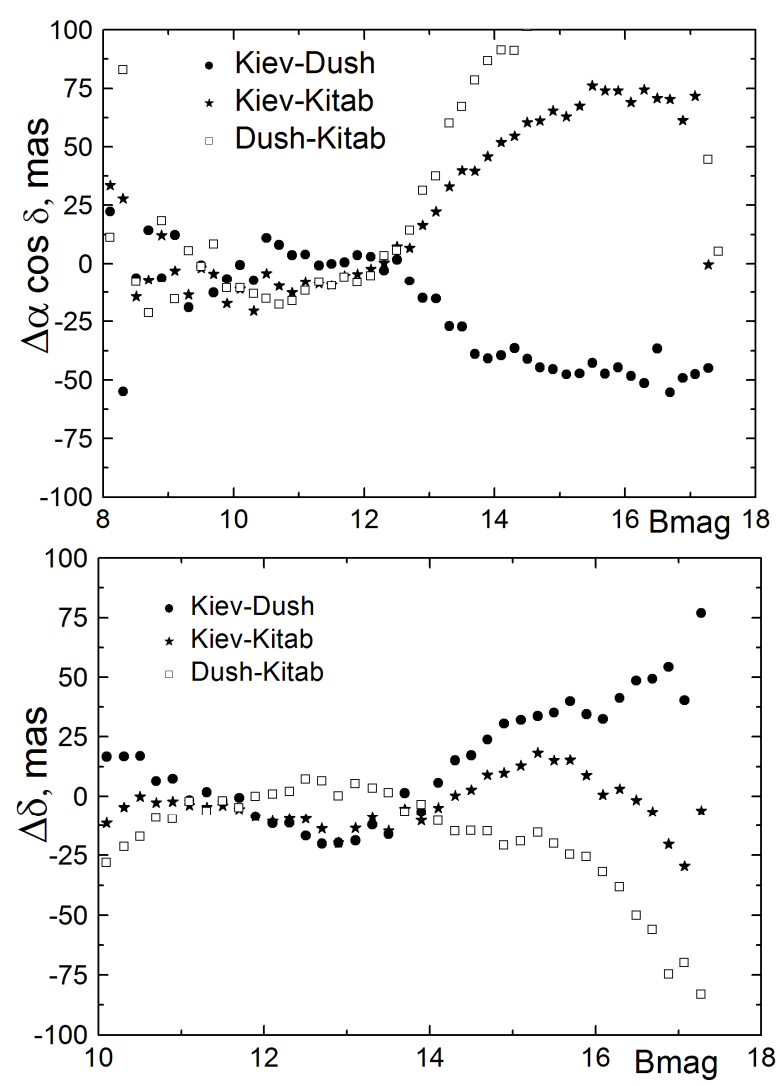

Figure 1: The systematic differences of stellar position of FON project catalogues: KIEV-DUSHANBE (black dots), KIEV-KITAB (asterisks) and DUSHANBE-KITAB (open rectangle) depending on the B-magnitude of FON-KIEV.

The estimations of external accuracy of stellar positions of FON project catalogues are some functions of stellar magnitude and equal to about 50 mas for brightest stars in the range of reference Tycho-2 stars for FON-KIEV and FON-KITAB data and about 120 mas for FONDUSHANBE data. After 12 stellar magnitudes we can see the significant increasing up to 250 mas for FON-KIEV and FON-KITAB data and up to 350 mas for FONDUSHANBE data (Figure 2).

These external estimations of positional precision of FON project catalogues are in a very good agreement with their internal accuracy at the mean epoch of observation. The systematic differences of internal accuracy minus external estimations of positional precision as function of stellar magnitude are presented in the figure 3 . The mean values of these systematic differences are not more than 30 mas for brightest stars.

From the figure 3 we can see clearly that the internal accuracy of stellar position is systematically overestimated for the faintest stars of FON-KIEV and FON-DUSHANBE catalogues. On the other hand it is underestimated in this magnitude range for the stellar position of FON-KITAB catalogue.The noted facts should be taking into account in course that to creating of all catalogues of FON project the only data from plates of digitized astronegatives was used without any CCD-observations. For example, the positional precision of 2MASS (Skrutskie et al., 2006) stars catalogue obtained from CCD-observations with the same pixel resolution is about 50-150 mas.
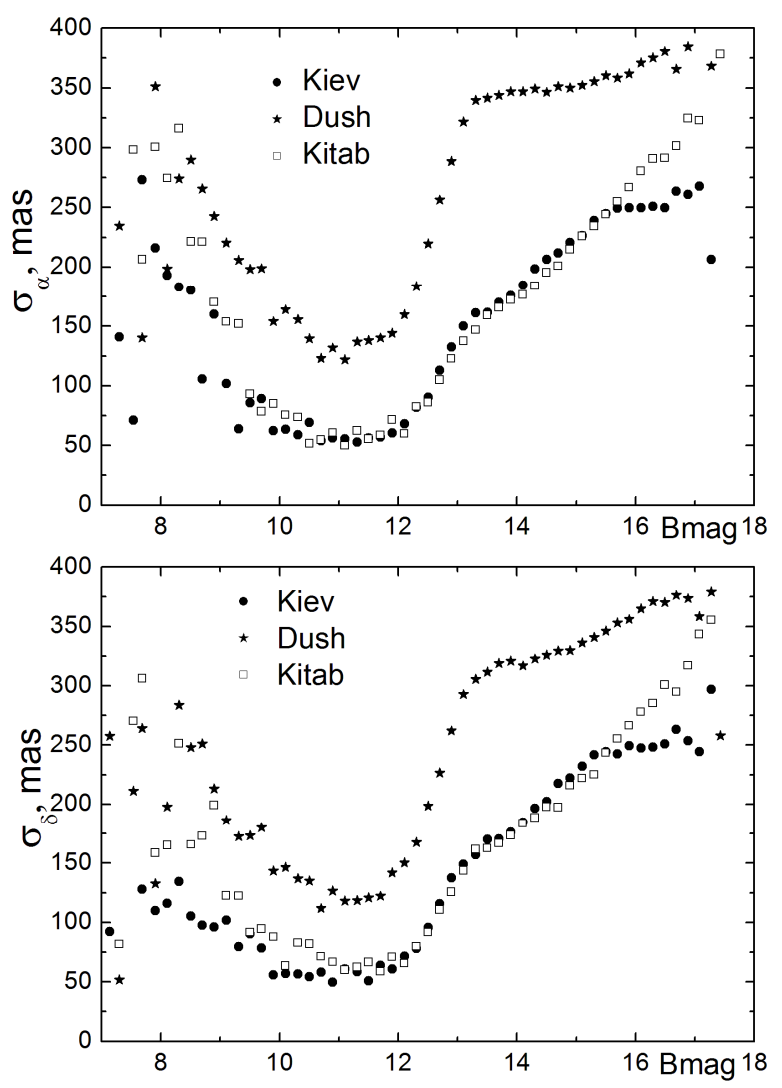

Figure 2: The standard deviations of stellar position of FON project catalogues: KIEV (black dots), DUSHANBE (asterisks) and KITAB (open rectangle) obtained by Wielen method depending on the B-magnitude of KIEV
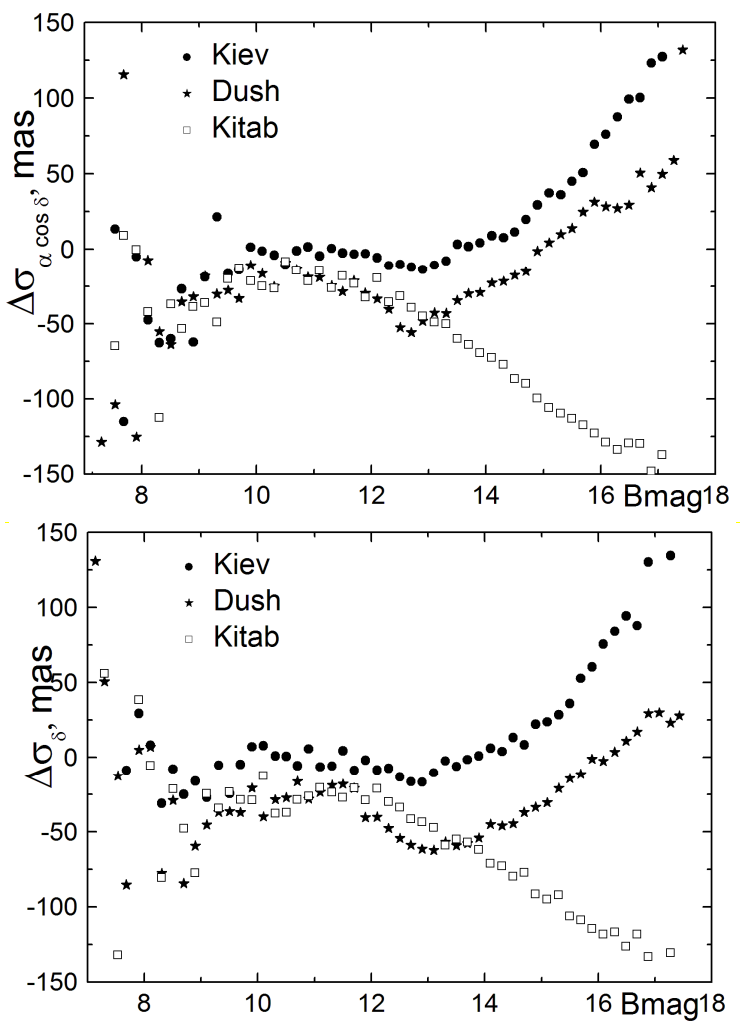

Figure 3: The systematic differences of external estimations and internal accuracy of the positional precision as function of stellar magnitude of FON project catalogues: KIEV (black dots), KIEV-KITAB (asterisks) and DUSHANBE-KITAB (open rectangle) depending on the B-magnitude of KIEV 


\section{Conclusion}

The external accuracy of stars position of catalogues FON project are good agreement with their internal accuracy and equal from 50 and 350 mas for brightest and faintest stars correspondingly.

Random error of the objects positions is within 50 to 250 mas for the FON-KIEV and FON-KITAB catalogues, and in two times more for the positions in the FONDUSHANBE catalogue - within 150 to 400 mas. This is due to the quality of scanned material.

The usage of high-precision reference catalogue in the whole range of magnitudes (for example, PMA or GaiaDR2) for the reduction will eliminate the brightness equation and improve the stars position both systematically and randomly.

The research results of astrometric and photometric characteristics of the FON project catalogues allow making the following conclusion. The positions and photometric measurements of objects in the FON project catalogues are obtained and they correspond to the accuracy for ground based photographic observations. The obtained observational data makes it possible to create a catalogue of positions and proper motions of the Northern Sky.

\section{References}

Akhmetov V.S. Fedorov P.N., Velichko A.B., Shulga V.M.: 2017, MNRAS, 469, 763.

Akhmetov V., Dmytrenko A., Khlamov S.: 2018, IEEE CSIT, 13, 266.

Andruk V.M., Pakuliak L.K., Golovnia V.V. et al.: 2015, Odessa Astron. Publ., 28, 192.

Andruk V.M., Golovnia V.V., Ivanov G.A. et al.: 2016a, Kinem. Phys. Cel. Bodies, 32, N1, 38.

Andruk V.M., Pakuliak L.K., Golovnia V.V. et al.: 2016b, Kinem. Phys. Cel. Bodies, 32, N5, 260.

Andruk V.M. et al.: 2017, Odessa Astron Publ., 30, 159.

Gaia Collaboration et al.: 2018, $A \& A$ 616, A1.

Mullo-Abdolov A., Kokhirova A., Relke H. et al.: 2017, Odessa Astron Publ., 30, 186.

Skrutskie M.F. et al.: 2006, ApJ, 131, 1163.

Vavilova I.B. et al.: 2012, Kinemat. Physics Celest. Bodies, 28, N2, 85 .

Yuldoshev Q.X., Muminov M.M., Ehgamberdiev Sh.A. et. al.: 2017a, Odessa Astron Publ., 30, 205.

Yuldoshev Q.X., Ehgamberdiev Sh.A., Muminov M.M. et al.: 2017b, Kinem. Phys. Cel. Bodies, 33, N5, 250.

Yuldoshev Q., Protsyuk Yu., Relke H. et al.: 2019, Astron. Nakhr., 58, In press.

Wielen R.: 1995, $A \& A, \mathbf{3 0 2}, 613$. 